\title{
LA DECADENCIA DE DURANGO DURANTE EL SIGLO XX. UNA MIRADA A LA HISTORIA DEL NORTE MEXICANO $^{\text {I }}$
}

\section{LUIS ABOITES AGUILAR ${ }^{2}$}

"Por décadas, Durango ha sido considerado el Chiapas del Norte". ${ }^{3}$

\section{RESUMEN}

4 ste trabajo estudia la decadencia demográfica y económica del estado de Durango a lo largo del siglo XX. En 1900 Durango era la entidad federativa más poblada y rica del norte mexicano, rasgos que fue perdiendo en las siguientes décadas. En el marco de ese declive estalló el movimiento estudiantil de 1966 con una demanda sorprendente: la industrialización, que implicaba suspender el traslado del mineral del Cerro del Mercado a la Fundidora Monterrey. Los fenómenos anteriores llevan a plantear un asunto fiscal de fondo: la escasa recaudación tributaria obteni-

1 Agradezco la dictaminación anónima, que ha sido de gran ayuda para aclarar el argumento. También expreso mi gratitud con las personas entrevistadas y con la familia Meléndez Torres, entrañables duranguenses.

2 Profesor-investigador de El Colegio de México. México. Correo electrónico: laboites@ colmex.mx

3 Frase inicial de la entrevista con el entonces gobernador del estado, Ismael Hernández Deras, El Siglo de Durango, sábado 20 de marzo de 2010. 
da en Durango, lo que se considera otro indicio de la decadencia local. Se trata en suma de un ensayo de interpretación que busca promover la investigación y la reflexión sobre las peculiaridades de la economía y la sociedad del norte mexicano en el siglo XX. El contraste con la trayectoria chihuahuense es casi obvio.

Palabras clave: Siglo XX; norte de México; Durango; población y economía; movimiento estudiantil; impuestos .

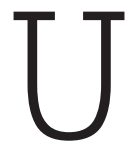
no de los capítulos más sobresalientes de la historia norteña del siglo xx es, sin lugar a dudas, la trayectoria del estado de Durango. Representa un mentís o, al menos, un poderoso matiz al "gran siglo norteño", noción referida a la prosperidad demográfica y económica del siglo xx, iniciada en las últimas décadas del siglo XIX. El surgimiento de la moderna Comarca Lagunera y el asombroso crecimiento industrial de Monterrey fueron los bastiones iniciales de esa prosperidad. Pero a diferencia de otras entidades norteñas, que junto a La Laguna y Monterrey vivieron años de esplendor durante las primeras seis o siete décadas del siglo xx, Durango se estancó y aun vino a menos. Tal vez lo que nos está diciendo la experiencia de esta entidad es que el auge general trajo consigo el deterioro de algunas zonas del propio Norte (escrito así, con mayúscula); o quizá sea que, salvo su porción lagunera y la zona más cercana a Parral, Durango no es parte del Norte en más de un sentido. Y es que la caída ha sido por demás notable. Los censos de población aportan un primer indicio general: mientras que en 1921 el estado de Durango tenía más habitantes que Nuevo León, en 2000 el número de neoleoneses casi triplicaba al de duranguenses. ${ }^{4}$

4 Por "Norte" se entiende aquí, en una división gruesa, los seis estados fronterizos (Baja California, Sonora, Chihuahua, Coahuila, Nuevo León y Tamaulipas) más Baja California Sur, Durango y Sinaloa. Todos los cálculos sobre la población duranguense y del Norte, en general, se basan en varios cuadros de la primera sección de EHM (2014). En una perspectiva más amplia, puede decirse que a inicios del siglo xx aún era visible la estructuración poblacional del viejo septentrión novohispano, cuya principal provincia era la Nueva Vizcaya. En 1900, los estados de Durango y Chihuahua albergaban al $33 \%$ de los habitantes del Norte. Pero el siglo xx hizo declinar tal preponderancia: en 
El objetivo de este trabajo es trazar de manera gruesa algunos de los principales indicadores de la decadencia duranguense a lo largo del siglo xx y, al hacerlo, tratar de indagar sobre la naturaleza de la economía y la política del Norte mexicano. En particular, se propone la hipótesis de que la decadencia duranguense tiene un sustento rural de primer orden. A diferencia del resto de los estados norteños (con excepción de Nuevo León y Baja California Sur), Durango no logró expandir la frontera agrícola de riego a lo largo del siglo xx. De hecho, llegó a ese siglo con el proceso consumado. En efecto, en la década de 1900 la porción duranguense de la Comarca Lagunera, encabezada por la empresa de Tlahualilo desde 1885 y a la vez manifestada por el surgimiento del municipio de Gómez Palacio en 1905, ya había sido abierta. Después de esa fecha no sumó ninguna otra zona agrícola similar a La Laguna. Este estancamiento contrastó muy pronto con el dinamismo de los demás estados que sí lograron ampliar la frontera agrícola de riego. En 1971, sin contar la porción lagunera, había apenas 12840 hectáreas de riego en el estado, con la peculiaridad de que esa corta superficie se hallaba repartida en 20 zonas; la más grande de ellas, El Tunal, contaba con poco más de 6000 hectáreas. ${ }^{5}$ Tal es la matriz del declive duranguense, según esta propuesta.

Como se ve, la trayectoria de esta entidad fue muy distinta a la más conocida y estudiada de los valles del Yaqui, Mexicali, Culiacán, Los Mochis y Bajo Bravo, cuyas superficies de riego superan (o superaban) cada uno las doscientas mil hectáreas. Ni siquiera contó con una zona más pequeña, como la del distrito de riego de Delicias, en Chihuahua, de apenas sesenta mil hectáreas. Ese conjunto de zonas agrícolas, además de otras (la misma Comarca Lagunera), ha merecido gran atención por parte de la historiografía económica de los últimos treinta años, como apunta bien un dictaminador. Pueden citarse numerosos estudios, pero acaso

2010 sus habitantes apenas eran $21 \%$ del total norteño. Sobre la Nueva Vizcaya en el siglo xvIII, véase Jones (1988).

5 Anuario estadístico de los Estados Unidos Mexicanos, 1970-1971 (1973), cuadro 10.5, p. 492. En una monografía de 1968 se da otra cifra: la superficie de riego duranguense, sin considerar La Laguna, ascendía a 40000 hectáreas (La economía del estado de Durango [1968], pp. 17-19). 
los más significativos son los de Almaraz (Mexicali), Carrillo (valle de Culiacán), Cerutti (La Laguna y valle del Yaqui), Rivas Sada (La Laguna) y Walsh (Bajo Bravo). ${ }^{6}$ El mismo dictaminador tiene razón cuando señala que de ese conjunto de estudios, se obtiene una visión muy distinta del Norte durante el siglo xx a la que se expone en este trabajo sobre Durango. De aquellos estudios se desprende una historia de innovación tecnológica, crecimiento productivo y prosperidad empresarial; en una palabra, de notorio avance de la modernidad capitalista. Pero justamente de lo que se trata es de distinguir los "muchos nortes", no de uniformarlos. Tal distinción es lo que interesa subrayar aquí. A diferencia de aquellos, este trabajo propone una visión acaso más compleja del Norte, incorporando sus porciones empobrecidas a lo largo del siglo xx. Aquellos estudios ni por asomo atienden las zonas periféricas, las áreas y actividades "marginales" (agricultura de temporal, por ejemplo). Interesarse por Durango (o por las porciones serranas de Sinaloa, Sonora y Chihuahua) obliga a tomarlas en cuenta.

El mismo dictaminador expresa su desacuerdo con el estudio de una entidad federativa en lugar de profundizar en una zona específica. Tal desacuerdo se basa en la desconfianza que provoca la muy mala calidad de la información disponible por entidad federativa, en particular aquella que mide el producto interno bruto (PIB). Tiene toda la razón, pero no hay opción. Aquí se emplea esa información para proponer tendencias generales que de otro modo sería imposible hacer; además, investigaciones ulteriores (ojalá que de jóvenes historiadores) podrán mostrar la ineficacia e insuficiencia del enfoque metodológico seguido aquí. Pero también podrían mostrar su utilidad, considerando las grandes semejanzas que guarda la trayectoria económica duranguense, basada en fuentes muy deficientes, con la decadencia demográfica, documentada esta con una fuente no cuestionada en absoluto: los censos de población. Sea lo que sea, este trabajo trata de mostrar que la historia norteña del siglo xx no se resume en la prosperidad de los valles agrícolas mencionados y que dicha historia también

6 Almaraz (2007); Carrillo (2013); Carrillo y Rivas Sada (2016); Cerutti (2006); Cerutti y Almaraz (2013); Rivas Sada (2011); y Walsh (2008). 
está hecha de procesos de empobrecimiento, estancamiento y decadencia. ¿O acaso lo único que resta por hacer es repetir o reiterar al infinito la visión del milagro económico norteño del siglo xx?

Pero hay otras razones del declive duranguense que una investigación detallada debe esclarecer. Además de no contar con grandes distritos de riego, otras dos carencias distinguen a Durango: frontera y costa. Al no estar situado en el lindero con Estados Unidos, Durango perdió la posibilidad de contar con una ciudad fronteriza pujante. Además, la segunda y tercera ciudades del estado, Gómez Palacio y Lerdo, respectivamente, se vincularon más con Torreón y Coahuila que con la economía duranguense. Tampoco recibió el impulso de un puerto, a pesar de la cercanía de Mazatlán que la sierra Madre relativiza en gran medida. Tampoco de un desarrollo industrial significativo como el de Monterrey o, al menos, el de la ciudad de Chihuahua. Ni la minería ni tampoco la vasta explotación forestal y ni siquiera la ganadería o la expansión de la agricultura de temporal, actividades de gran peso en la entidad, lograron contrarrestar el fenómeno. El arribo de los menonitas a Nuevo Ideal en la década de 1920 estuvo lejos de desencadenar un proceso urbano equivalente al de Cuauhtémoc, en el oeste chihuahuense. Los menonitas llegaron a ambos lugares en 1922, pero tomaron rumbos muy distintos. En Chihuahua, el florecimiento de las colonias menonitas contribuyó al surgimiento de la ciudad y del municipio de Cuauhtémoc en 1927, mientras que en Durango la localidad de Nuevo Ideal alcanzó dicha categoría política seis décadas más tarde: en 1989. En 2010, Cuauhtémoc, para entonces la tercera ciudad chihuahuense, rebasaba los ciento catorce mil habitantes; los de Nuevo Ideal apenas eran la décima parte y por ello no alcanzaban a formar una ciudad, si por tal se entiende una localidad con más de quince mil habitantes.

Este trabajo también intenta conectar la decadencia duranguense, caracterizada en principio en términos demográficos y económicos, con dos componentes más, ambos de índole política: por un lado, con el movimiento estudiantil de 1966, cuya principal demanda era la industrialización; y por otro, con las posturas gubernamentales en torno al rezago fiscal de la entidad. El propósito 
es mostrar que el declive duranguense influyó decisivamente en las peculiaridades de la vida política local, que también conoce variantes a lo largo y ancho del Norte. El ataque guerrillero a Madera, de 1965, fue singularidad chihuahuense, no norteña. El breve apartado final da cuenta de los principales hallazgos y, sobre todo, de las numerosas interrogantes que resultan del estudio realizado.

\section{POBLACIÓN Y ECONOMÍA}

En términos demográficos hay, al menos, tres indicadores de la singularidad local: el bajo crecimiento general, la débil urbanización y el lento crecimiento de la ciudad capital.

El primer indicador es simple. Si la población norteña creció casi diez veces entre 1900 y 2000, la de Durango apenas lo hizo cuatro veces. Podría alegarse de entrada el impacto de la Revolución de 1910, ya que Durango fue por mucho la entidad norteña que más población perdió: 30 \% menos entre 1910 y 1921. Pero no parece suficiente, en vista de la potencia de las otras tendencias que se expondrán enseguida.

El cuadro 1 muestra el ritmo de crecimiento demográfico de Durango, Nuevo León y el Norte por periodos aleatorios, ${ }^{7}$ del cual quedan claros, al menos, dos aspectos: el primero es que en todos los casos Durango creció menos que el Norte y menos aún que Nuevo León; y el segundo aspecto es que la diferencia entre ellos se agrandó después de 1950. Si se fija el atento lector, el periodo en el que las tasas de crecimiento son más parecidas es 1930-1950, lo que probablemente tuvo que ver con el auge de la actividad algodonera de La Laguna. Si es así, podría pensarse que el declive de esa actividad en la Comarca Lagunera después de 1950 ayuda a explicar la creciente distancia en el ritmo de crecimiento entre Durango y el Norte en su conjunto, lo mismo que con Nuevo León, cuya población aumentó a gran ritmo justamente desde entonces. ${ }^{8}$

7 La inclusión de Nuevo León se explica por el conflicto estudiantil en torno al cerro de Mercado y la Fundidora Monterrey, que se expondrá en el siguiente apartado.

8 Una pista que parece mostrar que esta idea no es del todo descabellada, se refiere al desplome del crecimiento de la población de la zona metropolitana de Torreón (que incluye a Gómez Palacio y Lerdo, ambas localidades duranguenses) después de 1950. 
Por lo anterior, no parece casualidad el cambio drástico del lugar de Durango en el escenario norteño del siglo xx: mientras que en 1900 era la entidad más poblada, a partir de 1950 era ya la penúltima (siendo Baja California Sur la última). En 2000 no había cambio alguno, salvo que la distancia entre Durango y Baja California Sur se había acortado notablemente. En 1950 la diferencia a favor de Durango era de más de diez veces; en 2000, de apenas 3.4 veces. De seguir así, llegará el tiempo en el que Baja California Sur, de muy rápido crecimiento en los últimos años, supere a Durango en este rubro. ${ }^{9}$

Cuadro 1. Crecimiento poblacional de Durango, Nuevo León y el Norte, 19002000 (número de habitantes y tasas de crecimiento anual promedio)

\begin{tabular}{cccccccc}
\hline & Durango & $\begin{array}{c}\text { Nuevo } \\
\text { León }\end{array}$ & Norte & TCAP* $^{*}$ & Durango & $\begin{array}{c}\text { Nuevo } \\
\text { León }\end{array}$ & Norte \\
\hline 1900 & 370307 & 327937 & 2107921 & $1900-1930$ & 0.29 & 0.81 & 1.07 \\
\hline 1930 & 404364 & 417491 & 2901416 & $1930-1950$ & 2.24 & 2.90 & 2.85 \\
\hline 1950 & 629874 & 740191 & 5089832 & $1950-1970$ & 2.02 & 4.23 & 3.53 \\
\hline 1970 & 939208 & 1694689 & 10181924 & $1970-2000$ & 1.46 & 2.76 & 2.45 \\
\hline 200014486613834141 & 21052222 & $1900-2000$ & 1.37 & 2.49 & 2.33 \\
\hline
\end{tabular}

* Tasas de crecimiento anual promedio.

Fuente: elaboración propia con base en EHM (2014); cuadros de la primera sección.

Este comportamiento demográfico tiene que tomar en cuenta un hecho singular: Durango fue, desde 1930 y durante el resto del siglo, la única entidad norteña que perdió población vía emigración de manera sostenida y creciente (cuadro 2). Baja California Sur y Sinaloa también formaron parte de esa lista, pero en algún momento la abandonaron. Coahuila, no por coincidencia compañero de Durango en La Laguna, también empezó a perder población a causa del mayor número de emigrantes que de inmigrantes, pero lo hizo hasta 1970 (en realidad desde 1960). Esa con-

De 5.37 \% anual en 1930-1950, la tasa cayó a 4.32 \% en 1950-1970 y a 2.81 \% entre 1970 y 2000. Estimación elaborada con base en Garza (2005), cuadros A1-A3.

9 El Conteo de Población de 2015 confirmó esta tendencia, pues arroja una diferencia de apenas 2.5 veces, aun favorable a Durango. 
dición deficitaria es rasgo duranguense del siglo xx, pues en los años de 1895-1910 Durango aparecía como importante receptor de migrantes, incluso era más atractivo que Nuevo León y Chihuahua. ${ }^{10}$ Si el lector se asoma de nuevo al cuadro 2, apreciará lo que acaba de decirse en cuanto al saldo favorable entre emigrantes e inmigrantes de Durango en 1900, el cual presenta la otra cara de la moneda: la prosperidad demográfica de Nuevo León. Esta entidad, junto con Baja California y Tamaulipas, fue una de las que mejores cuentas registró con respecto a la migración interna, especialmente durante la segunda mitad del siglo. Y es de notar que el saldo negativo de Durango y el superávit migratorio de Nuevo León son tendencias duraderas; ambas se sostienen hasta el año 2000.

La gráfica 1 intenta expresar de mejor modo la singular trayectoria de Durango que ofrecen las cifras de la última columna del cuadro 2. Esta se refiere al cociente que resulta de la división entre emigrantes e inmigrantes. Así, si el cociente es igual a uno significa que el número de emigrantes e inmigrantes es idéntico; si es menor a uno quiere decir que se registra un saldo migratorio positivo o favorable; pero si es mayor a uno, se trata entonces de un saldo negativo. Se destaca primero que el índice de Durango, Nuevo León y el Norte era casi idéntico en 1900; en segundo lugar, nótese que ni Nuevo León ni el Norte exhiben un saldo negativo (mayor a uno) a lo largo del siglo; y por último, y en claro contraste, que la pérdida duranguense crece sostenidamente desde 1930 y con más fuerza después de 1950; la pérdida se modera después de 1970. La curva duranguense ilustra su trayectoria general, muy distinta a la del Norte. Como se ve, la curva norteña es muy parecida a la de Nuevo León.

10 Guerra (1988), I, pp. 338-345. 
Cuadro 2. Migración interna en Durango, Nuevo León y el Norte mexicano

\begin{tabular}{|c|c|c|c|c|}
\hline \multicolumn{5}{|c|}{$(1900-2000)$} \\
\hline & Inmigrantes & Emigrantes & Saldo & $\begin{array}{l}\text { Emigrantes/ } \\
\text { Inmigrantes }\end{array}$ \\
\hline \multicolumn{5}{|c|}{1900} \\
\hline Durango & 46232 & 25856 & 20376 & 0.56 \\
\hline Nuevo León & 42117 & 18773 & 23344 & 0.44 \\
\hline Norte & 236777 & 102664 & 134113 & 0.43 \\
\hline \multicolumn{5}{|c|}{1930} \\
\hline Durango & 51527 & 72933 & -21406 & 1.42 \\
\hline Nuevo León & 63718 & 49562 & 14156 & 0.78 \\
\hline Norte & 499752 & 286398 & 213354 & 0.57 \\
\hline \multicolumn{5}{|c|}{1950} \\
\hline Durango & 68826 & 115242 & -46416 & 1.67 \\
\hline Nuevo León & 135938 & 94142 & 41796 & 0.69 \\
\hline Norte & 915152 & 551877 & 363275 & 0.60 \\
\hline \multicolumn{5}{|c|}{1970} \\
\hline Durango & 62351 & 241018 & -178867 & 3.87 \\
\hline Nuevo León & 399866 & 127670 & 272196 & 0.32 \\
\hline Norte & 1760619 & 1153809 & 606810 & 0.66 \\
\hline \multicolumn{5}{|c|}{2000} \\
\hline Durango & 163607 & 447731 & -284124 & 2.74 \\
\hline Nuevo León & 827453 & 228453 & 559000 & 0.27 \\
\hline Norte & 4336186 & 2508434 & 1827752 & 0.58 \\
\hline
\end{tabular}

Fuente: elaboración propia con base en Sobrino (2010); cuadro A3. 
Gráfica 1. Saldo de la migración interna en el Norte 1900-2000

(número de emigrantes entre número de inmigrantes)

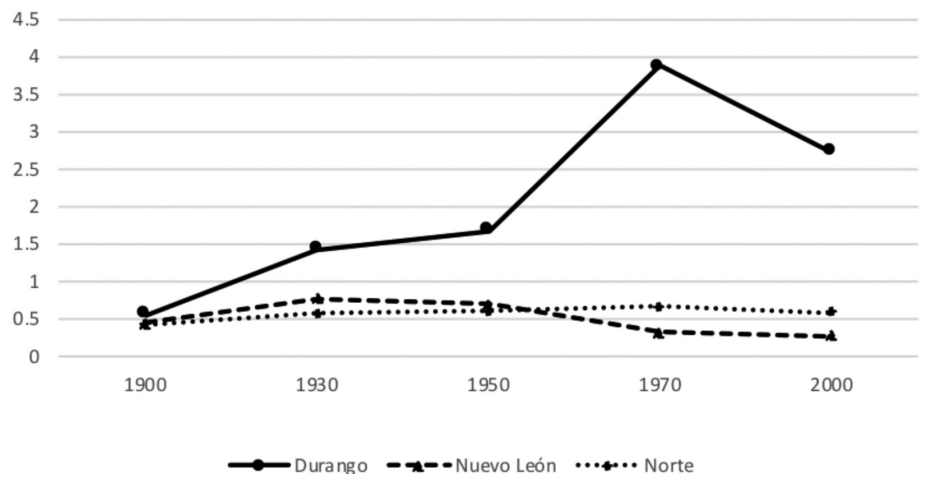

Fuente: cuadro 2.

Buena parte del éxodo de duranguenses tuvo como destino los estados de Sinaloa, Sonora y Nuevo León. Pero también cruzaron la frontera para trabajar y/o establecerse en el vecino país. En 1926, según el ingenioso cálculo de Manuel Gamio, Durango era la quinta entidad federativa mexicana con mayor número de migrantes en Estados Unidos. Por ello, no parece descabellado ubicar a Durango como parte de la llamada "región tradicional" de migración desde entonces, junto con Michoacán, Guanajuato y Jalisco. ${ }^{11}$ Por desgracia, no abunda la información sobre el lugar de origen de los mexicanos en Estados Unidos. Una de las fuentes disponibles, con datos de 1990 y 2005, arroja que en 1990 había 202038 duranguenses en Estados Unidos, cifra que aumentó a 384192 en 2005, es decir, 90 \% más. Ningún otro estado norteño registró un movimiento de semejantes proporciones. En 1990, los 202038 migrantes representaban $15 \%$ de la población duranguense total, mientras que los de

11 Gamio (1930), p. 13. En general, los estudios sobre migración hacen una delimitación del Norte idéntica a la empleada en este texto (véase nota 4), salvo por Durango. En esos estudios, Durango aparece incluido en la "región tradicional", la de mayor aportación de migrantes, junto con los siguientes estados no norteños: Zacatecas, San Luis Potosí, Guanajuato, Aguascalientes, Nayarit, Jalisco, Colima y Michoacán. Véase Conapo (2005), cuadro I.1. 
2005 representaban $25 \% .^{12}$ En suma, el estado de Durango perdió una proporción significativa de su población desde 1930 (en realidad desde 1921) a causa de la emigración de una parte creciente de su población. Esta es una de las razones que explica su bajo ritmo de crecimiento demográfico; al mismo tiempo, es una de las razones que lleva a pensar que esta entidad es "poco norteña".

El segundo indicador demográfico que distingue al estado de Durango, se refiere a la lenta urbanización. Desde 1950 (y hasta 2000) fue la entidad federativa norteña con menor proporción de población urbana. A diferencia de otros estados, en Durango se formaron pocas ciudades, apenas tres hasta antes de 1990 (la capital, Gómez Palacio y Lerdo). En 1990 se sumaron otras dos (Santiago Papasquiaro y El Salto), pero ambas con menos de 16003 habitantes. Dos nuevas ciudades en extremo modestas. El censo de 2000 no sumó ninguna. Así que en el año 2000 Durango contaba con apenas cinco localidades urbanas, una con poco más de 400 000 habitantes (la capital), otra con 210 000, otra con casi 59000 y dos con menos de 25000 habitantes. En ese mismo año, como contraste, el área metropolitana de Monterrey superaba los $3.2 \mathrm{mi}$ llones, y las de Tijuana y Ciudad Juárez contaban con más de 1.2 millones cada una. No por otra razón todavía en 2000 el grado de urbanización de Durango era el más bajo del Norte (apenas 55 \%) frente al promedio de $82 \%$ del Norte en su conjunto. ${ }^{13}$ Si se revisa con cuidado el inventario de Gustavo Garza (2005) en la obra citada, se verá que el resto de las entidades federativas, salvo Nuevo León, fueron sumando localidades urbanas a lo largo del siglo xx. No debe olvidarse, además, que durante la década de 1950, una de las más secas del siglo xx, la economía de la Comarca Lagunera enfrentó grandes dificultades a causa del paulatino abandono del cultivo algodonero y por el desempleo resultante. Los nuevos gigantes agrícolas (el Bajo Bravo y los valles de Sinaloa y Sonora) desdibujaron aún más la antigua prosperidad lagunera. ${ }^{14}$ Sin duda, el desplome lagunero, por la importante contribución fiscal que

12 Conapo (2005), cuadros i.2 y i.3.

13 Estimaciones elaboradas con base en Garza (2005); cuadros A1-A3.

14 Sobre el declive lagunero, palpable ya en la década de 1950, véase Rivas Sada (2011), pp. 253-265; y Ramos Salas (2009), pp. 284-294. 
significaba el algodón para el gobierno duranguense, afianzó el declive. ${ }^{15} \mathrm{Y}$ como parte del declive, la débil urbanización.

El tercero y último indicador de la singularidad demográfica duranguense, se refiere a la trayectoria de su ciudad capital. En 1900 no había en el Norte una ciudad con mayor esplendor y número de habitantes que Durango, salvo por Monterrey en este último rubro. Era una de las ciudades más antiguas (1563), sede, por cierto, del primer obispado del septentrión novohispano (1620). El segundo obispado norteño, el de Linares-Monterrey, se creó 157 años después. Hoy día ese antiguo esplendor, derivado del auge ganadero y minero de fines del siglo xvIII, se aprecia en el centro histórico de la ciudad, hermosamente restaurado en años recientes. ${ }^{16}$ No parece arriesgado sostener que hoy día no hay en el Norte una ciudad con tal riqueza y diversidad monumental. Es una ciudad que invita a caminar, a vivir en paz, a diferencia de otras como Hermosillo o la ahora horrible ciudad de Chihuahua.

La situación general de Durango, y en particular la de su capital, se modificó drásticamente a fines del siglo XIX cuando, para furia de sus habitantes, el trazo del ferrocarril Central no siguió el camino Tierra Adentro sino uno de sus ramales, un tramo más corto aunque más despoblado, para proseguir desde Zacatecas hacia la frontera norte. ${ }^{17}$ Tal vez este trazo fue una especie de premonición de lo que se vendría en el siglo siguiente, y ello a pesar de que pocos años después se construyó el ramal ferroviario Durango-Torreón. Por otro lado, en 1880 se inició la explotación a gran escala del rico yacimiento de fierro del cerro de Mercado, situado en las goteras de la ciudad capital. Pero en 1920 la Fundidora de Monterrey, propiedad de Adolfo Prieto, adquirió la principal explotación del famoso cerro, lo que le permitió contar con grandes reservas de materia prima. Una historiadora apunta que el gigantesco yacimiento acabó beneficiando a Monterrey, no a Durango. ${ }^{18}$ ¿Acaso por ese vínculo con Monterrey el año de 1920 marca el inicio del declive local? Re-

15 Sobre la aportación tributaria de la actividad algodonera a la hacienda pública de los estados norteños, véase Aboites Aguilar (2013), pp. 246-266.

16 Vallebueno Garcinava (2005), pp. 54, 76-77 y 204.

17 Arreola Valenzuela (1995), pp. 40-41.

18 Villa Guerrero (1999), pp. 98-99. 
cuérdese que 1921 fue el último año en el que el estado de Durango registró un mayor número de habitantes que Nuevo León. El resto de la historia no sorprende. El lugar de la ciudad capital en la jerarquía urbana norteña es ilustrativo del rumbo general. Si en 1900 Durango era la segunda ciudad norteña por número de habitantes, en 1930 era la séptima, la novena en 1950, la onceava en 1970 y la doceava en 2000. A lo largo del siglo xx, Tampico, Ciudad Juárez, la ciudad de Chihuahua, Torreón, Tijuana, Mexicali, Hermosillo y Culiacán la alcanzaron y la dejaron atrás.

Pero estos tres indicadores demográficos (población estatal, urbanización y población de la ciudad capital) no son tan elocuentes del rumbo general como los que se refieren a la economía (cuadro 3). En este rubro puede decirse que Durango se derrumbó a lo largo del siglo, sobre todo en la primera mitad. En 1900 no solo era la entidad norteña con mayor número de habitantes, sino también la de una economía más próspera, si como tal se entiende el hecho de que era la de mayor contribución al PIB norteño (más de 21 \%) y al PIB nacional (5.3 \%). Tan grande fue la caída económica que su aportación se redujo sostenidamente hasta llegar en 1950 a apenas $6.9 \%$ con respecto al producto norteño y a $1.8 \%$ con respecto a la economía del país. Sin duda, la contracción duranguense de la década de 1940, justo cuando el país, Nuevo León y el Norte crecían a tasas cercanas al 6 \% anual, merece investigaciones concienzudas.

Como se dijo, después de 1950, a diferencia de la trayectoria demográfica, la economía duranguense recuperó bríos, pero su ritmo de crecimiento fue menor al del país, el Norte y Nuevo León. No en balde su participación porcentual en la economía norteña, y en la nacional, continuó en picada. Para el año 2000 Durango aportaba $4.7 \%$ del PIB norteño (contra $21 \%$ en 1900) y $1.7 \%$ del PIB nacional (contra 5.3 \% en 1900). En 2000 el PIB de Durango era el penúltimo del Norte, solo por encima del de Baja California Sur, tal y como ocurría en materia de población. La inauguración de La Jabonera en 1898, de una fábrica de dinamita, así como el auge del algodón, la minería y la explotación forestal en diversos puntos de la entidad eran indicios de una bonanza que, sin embargo, no 
logró consolidarse. ${ }^{19}$ La notable expansión de la agricultura temporalera después de 1930, otro tema que espera investigadores, no alcanzó a contrarrestar la debacle.

Cuadro 3. Producto interno bruto de Durango, Nuevo León, el Norte de México y de México, 1900-1960 (millones de pesos de 2008 y tasas de crecimiento anual promedio $)^{20}$

\begin{tabular}{cccccc}
\hline & 1900 & 1940 & 1950 & 1970 & 2000 \\
\hline Durango & 7459 & 13415 & 12724 & 34087 & 116015 \\
\hline Nuevo León & 5694 & 18042 & 31184 & 142922 & 638488 \\
\hline Norte & 35211 & 102659 & 182323 & 614449 & 2496443 \\
\hline México & 140200 & 385640 & 690242 & 2429052 & 9897365 \\
\hline $\begin{array}{c}\text { Durango/ } \\
\text { Norte }\end{array}$ & $21.4 \%$ & $13.1 \%$ & $6.98 \%$ & $5.55 \%$ & $4.65 \%$ \\
\hline $\begin{array}{c}\text { Durango/ } \\
\text { México }\end{array}$ & $5.3 \%$ & $3.47 \%$ & $1.84 \%$ & $1.40 \%$ & $1.17 \%$ \\
\hline & TCAP* & & & \\
\hline Durango & $1900-1940$ & $1940-1950$ & $1950-1970$ & $1970-2000$ \\
\hline Nuevo León & 1.48 & -0.53 & 5.05 & 4.17 \\
\hline Norte & 2.93 & 5.62 & 7.91 & 5.12 \\
\hline México & 2.71 & 5.91 & 6.26 & 4.78 \\
\hline
\end{tabular}

* Tasas de crecimiento anual promedio.

Fuente: elaboración propia con base en Appendini, "Producto bruto interno", s/f; cifras de 1970 en Inegi (1993), cuadro 1, y las de 2000, en Inegi (s/f), cuadro 1.

Del mismo modo que ocurría en términos de la población, en 1900 la economía duranguense superaba holgadamente a la de Nuevo León. Pero las cifras del cuadro 3 muestran que para 1940 la situación se había invertido. Nuevo León (es decir, Monterrey) había despegado, mientras que Durango se había venido abajo.

19 Sobre el esplendor económico duranguense de principios del siglo xx, véase Cerutti (1997); Arreola Valenzuela (1995), pp. 41-54; y Avitia Hernández (2013), II, pp. 26-119.

20 La conversión de precios de 1950 (Appendini) y de precios corrientes de 1970 y de 2000 a precios constantes de 2008 estuvo a cargo de la economista Itzaé Lizette Ortiz Lemus, a quien agradezco cumplidamente su trabajo. 
Hay que insistir en la necesidad de hacer una investigación minuciosa sobre este fenómeno.

Cabe subrayar por último la coherencia entre las cifras de la población y las económicas. Sin duda, la estimación del PIB es endeble, pero aun así es coherente con la trayectoria poblacional, que cuenta con mejor sustento en cuanto a fuentes. ¿No es acaso tal coherencia un indicio, al menos, de que la visión del piB estatal no anda del todo en el extravío?

\section{EL MOVIMIENTO ESTUDIANTIL DE 1966}

En el contexto de esta caída libre de la población y de la economía local debe ubicarse la movilización estudiantil de 1966, organizada en torno a una demanda en verdad sorprendente: la industrialización. Exigían que el mineral del cerro de Mercado dejara de enviarse a Monterrey y que se construyera una planta siderúrgica con el propósito de impulsar la industrialización de la ciudad. Ojalá se entienda ahora el porqué de la inclusión del estado de Nuevo León en las cuentas de las páginas anteriores. Es claro que el movimiento de 1966 expresa la estrecha liga entre Durango y Nuevo León, especialmente entre las dos capitales: una con un yacimiento de fierro y la otra con una fundidora. ${ }^{21}$

¿Qué peculiaridades tenía Durango que sus estudiantes se movilizaban no contra la opresión social ni contra el autoritarismo gubernamental o el de las autoridades universitarias ni tampoco a favor de la Revolución cubana o en apoyo a la extendida inconformidad rural que por esos años se vivía en el propio estado de Durango y en el de Chihuahua? ¿Por qué en lugar de hacerse eco de los aires de rebeldía y radicalismo que pululaban en el mundo en esos años, los jóvenes duranguenses exigían industrias e industriales, empresarios pues? Recuérdese que apenas un año

21 Este apartado se basa en las entrevistas realizadas en la ciudad de Durango los días 20 y 21 de noviembre de 2015 con los siguientes protagonistas del movimiento estudiantil: Rubén Vargas Quiñones, Juventino Rodarte y Jorge Contreras Casas. Asimismo, toma en cuenta una pequeña parte de la amplia bibliografía que ha generado el movimiento de 1966: Mijares Verdín (1996); Lucero González (2002); y Avitia Hernández (2003). 
antes en el vecino estado de Chihuahua un grupo guerrillero formado por maestros y agraristas había atacado el cuartel militar de Madera. Con ese ataque se había iniciado la época guerrillera en México, así como la feroz represión que pronto dio lugar a la llamada guerra sucia. Pero Durango parecía vivir en otra sintonía, en otra época, en otro mundo; un mundo que, sin embargo, formaba parte del mismo mundo y de la misma época norteña. ¿O cómo entender el deseo de los jóvenes duranguenses por formar una moderna burguesía? Quizá por esa densa complejidad este movimiento estudiantil es tan poco conocido fuera de Durango.

A principios de junio de 1966, cientos de estudiantes tomaron el cerro de Mercado y, con ello, paralizaron la explotación minera de la Fundidora de Monterrey. Además de la singular demanda proindustrialización, el movimiento nació vinculado a intereses empresariales. Cabe explicar. En 1949 el gobierno federal había decretado una veda forestal en la sierra duranguense (según algunos como revancha del gobierno por la demanda forestal de los rebeldes cristeros de la década de 1930), que fue levantada gracias a una concesión también federal otorgada en 1963 a Bosques Mexicanos, A. C., propiedad del empresario Gilberto Rosas Simbeck. Daba luz verde a la explotación de más de dos millones de hectáreas situadas al noroeste del estado. Una parte de la opinión pública local recibió con beneplácito la concesión, pero otros sectores, entre ellos un grupo de empresarios (encabezado por Fermín Núñez) y algunos universitarios, se inconformaron y exigieron la cancelación de la concesión otorgada a Rosas. Lo lograron, pues un nuevo decreto presidencial de fines de 1965 anuló el de 1963. Ante la adversidad, Rosas apoyó (algunos dicen que instigó) el movimiento estudiantil. A tal grado llegó ese apoyo que el empresario Rosas, con ayuda de la Cámara de Comercio local, formó un comité de abasto para dar sustento a los estudiantes posesionados del referido cerro. ${ }^{22}$

22 El nombre completo era "Comité de las Fuerzas Activas y Productivas para el Abastecimiento del Movimiento Estudiantil Pro-Industrialización de Durango". En Mijares Verdín (1996), p. 30. Los decretos mencionados aparecen en el Diario Oficial de la Federación, miércoles 26 de octubre de 1949, miércoles 15 de enero de 1964 y martes 14 de diciembre de 1965, respectivamente. Sobre la conexión de la veda de 1949 con la rebelión cristera, véase de nuevo a Mijares Verdín (1996), pp. 18-19. 
Por lo visto, Rosas, según algunos emparentado con el general Lázaro Cárdenas, de cuyo gobierno habría recibido jugosas concesiones para fabricar postes para el cableado eléctrico y durmientes para las vías del ferrocarril, buscaba revolver el río y sacar ganancia, es decir, recuperar la concesión forestal de 1963. No lo logró, entre otras cosas porque el comité de huelga de la universidad se mantuvo fiel a su demanda principal: poner fin a la explotación del mineral por parte de los capitalistas regiomontanos y promover, con ello, la industrialización local. Formado por estudiantes de la universidad y del tecnológico, pero también por preparatorianos y aun alumnos de secundaria, y por maestros, el movimiento paralizó la capital del estado durante los meses de junio y julio de dicho año. Padres de familia y el vecindario de la capital estatal, se sumaron con entusiasmo a la movilización. A la extraña bandera industrializadora y a la aún más extraña mancuerna empresariosestudiantes, debe sumarse la participación también extraña del general Salvador Rangel Medina, comandante de la zona militar, quien fungió no como represor sino como comprensivo consejero y activo promotor de las negociaciones entre las partes. ${ }^{23} \mathrm{El}$ muy conservador arzobispo Antonio López Aviña también secundó el movimiento, llamando a buscar una mejor repartición de la riqueza, sin dejar de advertir, sin embargo, del peligro que encerraban las "doctrinas extrañas". El llamado del jerarca católico no era retórico. El movimiento estudiantil pronto se dividió entre aquellos que permanecían en el cerro, más vinculados al comité de comerciantes que los alimentaba, y los del comité de huelga de la universidad local que noche tras noche realizaban mítines en la plaza principal y que atraían a numerosos vecinos. En el mitin del 15 de julio había participado el líder radical Álvaro Ríos, de la Unión General de Obreros y Campesinos de México (Ugocm). Por ese tiempo, Ríos encabezaba varias invasiones de predios en el norte de Durango y el sur de Chihuahua, e iba de paso a la capital del país en una de sus famosas caravanas. ${ }^{24}$ Para los empresarios

23 Urge saber más acerca del papel de los comandantes de las zonas militares en la vida política de los estados en estos años. Al respecto, véase Acosta Zavala (2015), p. 111 (Nuevo León); y Ornelas (2010), pp. 97-99 (Durango).

24 Al respecto, véase De la O Holguín (2015), pp. 90-95. 
del comité de abasto, lo mismo que para el general Rangel, el arzobispo y los gobiernos local y federal, el acercamiento entre estudiantes y agraristas era inadmisible. Quizá el fresco recuerdo del ataque guerrillero a Madera los horrorizaba. Lo cierto es que el comité de abasto intentó suspender los mítines de la plaza de Armas y aun censurar a los oradores. No parece descabellado pensar, entonces, que empresarios y autoridades gubernamentales locales apuraron el fin del conflicto ante el riesgo de que "su" movimiento se radicalizara. Incluso, se dice que Fidel Castro envió un telegrama solidario dirigido a "nuestros hermanos duranguenses" ${ }^{25}$ Pero no, los estudiantes duranguenses distaban de ser de izquierda, como lo expresan los entrevistados y como se lee en la bibliografía consultada. A diferencia de otras ciudades norteñas, en la ciudad de Durango la izquierda brillaba por su ausencia. Lo anterior no significaba que los estudiantes aceptaran mansa o ciegamente, al menos los del comité de huelga, las directrices empresariales. A los jóvenes duranguenses egresados de la universidad y del tecnológico les preocupaban sobremanera las escasas perspectivas que ofrecía el mercado laboral local. Por lo visto se trataba de una clase media urbana amenazada, que buscaba afanosamente un lugar en la deprimida economía local.

El conflicto se resolvió con la creación de una especie de alcabala que gravaba el traslado del mineral extraído del cerro de Mercado a Monterrey, consistente en una cuota de 4.50 pesos por tonelada, con la que se formaría un fondo de mejoras en el estado y para otorgar becas estudiantiles. Las autoridades también se comprometieron a hacer estudios para echar a andar la tan anhelada industria local, todo ello como fruto de las negociaciones sostenidas por los líderes estudiantiles con las autoridades federales en la Ciudad de México. Pero no mucho más. Así se explica la decepción generalizada que trajo consigo el anuncio del fin del movimiento. A varios líderes estudiantiles, se les acusó de vendidos y traidores, y con eso vivieron durante años. Días después del final del movimiento, ocurrió la desaparición de poderes en

25 Sobre Álvaro Ríos y el telegrama de Fidel Castro, véase Mijares Verdín (1996), pp. 30 y 33. 
el estado, lo que significó la caída del gobernador Enrique Dupré Ceniceros. Pero parecía más un ajuste de cuentas entre las altas esferas gubernamentales que un acontecimiento que pudiera cambiar en algo el desánimo generalizado de algunos habitantes de la capital estatal. ${ }^{26}$

Los estudiantes volvieron a movilizarse a principios de 1970. De nueva cuenta establecieron vínculos con empresarios (ahora inconformes por un alza de impuestos decretada por el gobierno estatal) y con vecinos en general; reiteraron la exigencia industrializadora y demandaron información detallada sobre el manejo del fondo formado con la recaudación de la cuota de 4.50 pesos. Pero, sobre todo, demandaron la destitución del impopular gobernador Alejandro Páez Urquidi, un empresario del ramo eléctrico avecindado antes en Monterrey. Volvieron a tomar el cerro de Mercado. Y aunque en esta ocasión el Ejército los desalojó, lograron paralizar la mina mediante el bloqueo de las vías ferroviarias. El movimiento de 1970 fue más largo que el anterior, pues se extendió de enero a junio. Pero tampoco consiguió mucho. Sí consiguió la libertad de varios presos políticos, la aparición de dos estudiantes desaparecidos y una rebaja en los impuestos estatales. El movimiento terminó de feo modo, entregando la bandera de la huelga universitaria a Luis Echeverría, candidato presidencial del Partido Revolucionario Institucional. El gobernador se mantuvo en el cargo y el cerro de Mercado continuó en manos regiomontanas. ${ }^{27}$ Una de las diferencias entre ambos movimientos es que del segundo surgieron varios líderes que más tarde se involucraron en la lucha urbana, un patrón muy similar al de Monterrey después del movimiento estudiantil de los primeros meses de 1971. En efecto, en la década de 1970, a diferencia del escenario de la década anterior,

26 Véase Moncada (1979), pp. 278-285. Fotografías del movimiento estudiantil se hallan en Avitia Hernández (2013), v, pp. 36-59. De la recaudación de dicha cuota, se obtuvieron los 100000 pesos que cobró una empresa alemana por un proyecto para establecer una fundidora en Durango. Véase Memoria Durango (1969), p. 19.

27 Sobre el segundo movimiento, menos estudiado que el primero, véase Ornelas (2010); entrevista con Miguel Palacios Moncayo. Ciudad de Durango, viernes 20 de noviembre de 2015; sobre el episodio de la entrega de la bandera, véase Gómez Villanueva (2015), pp. 129-130. 
aparecieron grupos de izquierda en la ciudad capital, en particular militantes maoístas vinculados al movimiento urbano popular. ${ }^{28}$

Al imponerse en ambos casos, los dueños de la Fundidora mostraban no solo su influencia económica y política, sino también una de las formas de estructuración de la economía norteña. Hace pensar, como apunta el estudioso Mijares Verdín (1996), en el "coloniaje interno". Se ignora si este autor tenía en mente el "colonialismo interno", la categoría elaborada en esos mismos años por el sociólogo estadounidense C. Wright Mills: ¿Nuevo León (Monterrey), la potencia dominante, y Durango, la zona dominada? Un estudioso apunta que durante la movilización de 1966 la Fundidora de Monterrey no sufrió afectación alguna, pero sí -y muy grave- en la de 1970, de mayor duración. De hecho, según él, la Fundidora no logró recuperarse del daño provocado por el segundo bloqueo al cerro de Mercado. La decisión del gobierno federal de construir la siderúrgica Lázaro Cárdenas-Las Truchas en 1973 restó importancia al yacimiento duranguense y, con ello, puso fin al sueño de impulsar la industrialización de la ciudad. Este mismo autor apunta que el surgimiento de la siderúrgica michoacana "marcó el cambio del eje de producción siderúrgica del noreste al suroeste del país". Otro observador cree que, en el fondo, los dos movimientos estudiantiles buscaban debilitar a la fundidora regiomontana y dar respaldo a su competidor, la familia Ancira, propietaria de la planta de Altos Hornos de México, en Monclova. Otro más apunta que la demanda duranguense surgía a destiempo, en el ocaso del milagro mexicano basado en el modelo de sustitución de importaciones. ${ }^{29}$

28 Entrevistas con Alberto Escudero Gómez. Ciudad de Durango, sábado 21 de noviembre de 2015 y domingo 17 de julio de 2016. Sobre el movimiento urbano popular duranguense de la década de 1970, véase Ramírez Sáiz (1986) y Meza Ponce (1984).

29 Mijares Verdín (1996), p. 22; González Casanova (2006), p. 422; sobre los efectos de los dos movimientos duranguenses en la Fundidora de Monterrey, véase Avitia Hernández (2003), pp. 65-68; la frase citada en p. 70. También sobre la afectación a la Fundidora, véase Correa Villanueva (1986), p. 46; sobre los Ancira de Monclova, entrevista con Juventino Rodarte, ciudad de Durango, viernes 20 de noviembre de 2015; y sobre la demanda anacrónica, entrevista con Miguel Palacios Moncayo, ciudad de Durango, viernes 20 de noviembre de 2015. Fotografías de este segundo movimiento se hallan en Avitia Hernández (2013), v, pp. 77-83. 
Con sus demandas, los dos movimientos estudiantiles parecen reflejar la mala situación de un estado que se consideraba rico en recursos naturales, pero de gran atraso económico por la carencia de industrias y buenas comunicaciones. Desde 1941 se afirmaba que "Las riquezas de Durango están dormidas [...] Durango no puede seguir viviendo en un rincón de la República, aislado de los centros comerciales e industriales del norte de México". ${ }^{30}$ Si en otros lugares se establecía una relación directa entre industrialización y desigualdad social (por ejemplo, en Monterrey), en Durango la demanda generalizada era precisamente la creación de la industria y, más allá, se exigía una clase empresarial de primer orden, como la regiomontana. Para dos de los entrevistados, el desenlace del movimiento de 1966 significó la extinción virtual de cualquier proyecto de los empresarios en la localidad, y aun de la propia clase empresarial en el estado. "Durango vive del presupuesto gubernamental", dice uno de ellos; "burguesía enana”, dice otro. ${ }^{31} \mathrm{La}$ carencia de una activa clase empresarial puede ser la clave para explicar la confluencia de actores tan diversos en los movimientos estudiantiles de 1966 y 1970. ¿Cómo explicar en ambos casos la cercanía de los empresarios con los estudiantes? Es evidente la necesidad de hacer un estudio a fondo acerca de la burguesía local a lo largo del siglo xx. A la luz del comentario de un dictaminador, cabe insistir en el argumento: no se está proponiendo que el conflicto estudiantil haya provocado "el atraso aparentemente estructural del estado”. Lo que se afirma es muy distinto: que el singular movimiento estudiantil es, en todo caso, reflejo del "atraso estructural" del estado.

La demanda del movimiento hace recordar el llamado que un general chihuahuense hacía en 1945 acerca de la necesidad de "monterreyizar" no a Durango, sino al país entero. ¿Tenía razón el general Ignacio Enríquez ? $^{32}$ No se sabe de un movimiento estudiantil similar al de Durango de 1966 en otro lugar del Norte

30 Véase el artículo de Heliodoro Dueñes, "El comercio y la industria de la ciudad de Durango", en Concanaco (1941), p. 38.

31 Los dos entrevistados son, respectivamente, Vargas Quiñones y Palacios Moncayo. Entrevistas realizadas el viernes 20 de noviembre de 2015 en la ciudad de Durango.

32 Enríquez (1945), pp. 44-45. 
ni en el resto del país; más bien, los estudiantes se movilizaban contra el poder gubernamental de las universidades y contra los privilegios de los empresarios privados y su estrecha cercanía con las autoridades locales y federales; protestaban contra la represión, el acaparamiento de la tierra (rural y urbana), los bajos salarios, o bien, contra el acoso yanqui a la Revolución cubana. La demanda tan distinta de la juventud de Durango es signo de la diversidad y complejidad norteña, nacional. No todo lo norteño del siglo xx, vale insistir, se resumía en los boyantes distritos de riego de la agricultura capitalista.

\section{POSTURAS GUBERNAMENTALES Y LA CUESTIÓN FISCAL}

Los gobernantes eran conscientes de las dificultades locales. En general, la explicación más socorrida, al menos en los informes de gobierno, tenía que ver con la geografía, calificada de desfavorable. Lo escabroso del territorio dificultaba las comunicaciones. En esos informes también abundan las referencias a limitaciones presupuestales, a la modestia de la obra pública y al estancamiento de los servicios. Dos ejemplos. En el informe de 1957 el gobernador aludía a la escasez de energía eléctrica, que había "impedido el crecimiento de la industria en nuestro territorio; por lo que al presente nuestro Estado depende fundamentalmente de la agricultura y la ganadería y año tras año todos compartimos la suerte favorable o adversa de estas actividades". En 1959 el mismo gobernador se quejaba de que el número de líneas telefónicas en la ciudad de Durango no había aumentado en las últimas décadas; seguían siendo las mismas mil trescientas de $1930 .^{33}$ Sin costa ni frontera, sin combustibles ni electricidad, Durango quedó "encerrado" entre la sierra Madre y la altiplanicie seca, y marginado también de las principales vías de comunicación, es decir, del ferrocarril Central, inaugurado en 1884. La carretera Panamericana, puesta en servicio a principios de la década de 1950, sí incluyó a la capital del estado, pero a fines de esa misma década empresarios laguneros y de Delicias, Chihuahua, lograron la construcción de un tramo

33 Memoria Durango (1957), p. 67; Memoria Durango (1959), pp. 22-23. 
directo entre ambas localidades, trazado junto a la línea del ferrocarril Central. Con ese tramo, que forma parte de la carretera 49, la capital de Durango (y Parral) quedó nuevamente al margen.

Una monografía de mediados de la década de 1960 describe las dificultades de la economía local. Cabe subrayar tres aspectos del diagnóstico: el escaso crecimiento demográfico, debido principalmente a la alta migración; la dependencia de la agricultura, en su mayor parte de temporal; y la escasa industrialización. La entidad no contaba con gasoductos y era remota la posibilidad de instalarlos. Ni la minería ni la ganadería eran opciones importantes en cuanto al empleo. En esos años la minería duranguense no era cosa menor: aportaba $10 \%$ de la producción nacional de hierro, $27 \%$ del oro, $12 \%$ de la plata, $12 \%$ del mercurio y $4 \%$ del plomo. Pero aun así los autores del estudio resaltaban el estancamiento local en el que ubicaban la actitud de los empresarios:

El carácter mismo de muchos hombres de empresa sufrió transformaciones. Perdió agresividad [...] Abandonó en gran medida otros campos importantes y ello suscitó estancamientos apreciables de la actividad económica. Con raras excepciones, Durango se rezagó entonces en su proceso de desenvolvimiento. ${ }^{34}$

El argumento se sostuvo en los años siguientes. En 1971 un diputado local caracterizaba el precario lugar de Durango en el país y, de paso, minimizaba la labor del gobernador del estado:

El haber adoptado el sistema federal para conformar nuestra República nos produce a las entidades con poco desarrollo, la posibilidad de recibir en algunas ocasiones un apoyo económico superior a nuestra participación para el fondo comunitario. Gran parte de lo logrado, tiene su raíz en la preocupación y en la simpatía que han sido causales de que el Estado reciba beneficios y recursos de la Federa-

34 La economía del estado de Durango (1968), p. 5; las noticias sobre la minería y la carencia de gas para la industria en pp. 24 y 39, respectivamente. Este estudio no incluye la porción duranguense de la Comarca Lagunera. Sobre el "antiguo y tradicional retraimiento" y aun el temor de los empresarios duranguenses en el campo económico, también véase Memoria Durango (1971), p. 43. 
ción de gran trascendencia, canalizados por instrucciones precisas y concretas de un distinguido amigo de Durango: el Señor Presidente de la República licenciado Luis Echeverría Álvarez. ${ }^{35}$

Por lo visto, la debilidad demográfica y económica se traducía en debilidad política. En lugar de gobernador, presidente de la República. El gasto federal parecía rubro decisivo en la economía de Durango, cuyo "poco desarrollo" lo distinguía de otras entidades y ciudades norteñas que se mostraban orgullosas de su condición económica, pero inconformes por su contribución al "fondo comunitario”. Al menos Nuevo León y Ciudad Juárez se quejaban precisamente de esa desigualdad, es decir, aportaban más de lo que recibían del gobierno federal. ${ }^{36}$

En su segundo año de gobierno, el gobernador Héctor Mayagoitia (1974-1980) hizo una declaración que es llamativa por varias razones: por la alusión a la Fundidora de Monterrey y al cerro de Mercado; por la referencia a las "varias décadas" de dificultades económicas y, quizá la más importante, porque asociaba el mal desempeño económico con la emigración de duranguenses:

Las deformaciones en el proceso de crecimiento de las que Durango ha sido víctima, no fueron advertidas con oportunidad ni con justeza, y propiciaron el que Durango no avanzara por varias décadas al ritmo del desarrollo del país; por el contrario, crearon volúmenes masivos de riqueza fuera de nuestro territorio y dieron origen al éxodo de nuestra población hacia otras entidades y aun hacia el extranjero. ${ }^{37}$

35 Memoria Durango (1971), pp. 108-109. El legislador era Máximo N. Gámiz.

36 Véase "Insistirá NL en pedir más recursos federales", nota del sábado 25 de septiembre de 1999, de David Carrizales y Andrés Morales; y “Trato injusto de la federación a Ciudad Juárez", nota de Miroslava Breach y Rubén Villalpando, del sábado 12 de febrero de 2000. Ambas notas en La Jornada. También véase el reclamo mexiquense en "Exigirán diputados y gobierno más recursos federales", nota del sábado 4 de diciembre de 1999, de María del Socorro Castañeda, corresponsal en Toluca de dicho diario.

37 Crónica Durango (s.p.i.), p. 119. Por desgracia, esta publicación, además de carecer de pie de imprenta, no da la fecha ni el lugar del discurso del gobernador, a quien se le llama "compañero". 
Un aspecto que, por lo general, no es tomado en cuenta en los estudios sobre las entidades federativas mexicanas es la capacidad recaudatoria de impuestos federales. La alusión del diputado Gámiz al "fondo comunitario" es una referencia a un fenómeno fiscal que debe estudiarse con todo detalle, para averiguar si estados como Durango recibían más dinero federal del que se lograba recaudar en su territorio. En este momento no hay modo de comprobar esa condición duranguense, pero sí es posible ofrecer pistas que pueden resultar orientadoras. Las muy escasas estadísticas sobre geografía tributaria federal del siglo xx indican precisamente que Durango era, después de Baja California Sur, la entidad norteña que menos impuestos federales recaudaba. Las únicas cifras disponibles, referidas a la recaudación del impuesto sobre la renta (ISR), se presentan en el cuadro $4 .{ }^{38}$ La pregunta que surge es si esa baja recaudación tiene relación con la decadencia general vista aquí.

Cuadro 4. Recaudación del impuesto sobre la renta en Durango y otras entidades federativas 1930-2005 (miles de pesos corrientes)

\begin{tabular}{cccccc}
\hline & 1930 & 1961 & $1979 *$ & 1997 & 2005 \\
\hline Durango & 319 & 13908 & 735 & 324378 & 777358 \\
\hline Nuevo León & 806 & 296704 & 12910 & 13140576 & 33118263 \\
\hline $\begin{array}{c}\text { B. C. Sur } \\
\text { Recaudación }\end{array}$ & 235 & 4633 & 336 & 566754 & 1827583 \\
\hline $\begin{array}{c}\text { total del Norte } \\
\text { Recaudación }\end{array}$ & 20650 & 927200 & 27578 & 29463079 & 74637764 \\
nacional (RN) & 4635800 & 173015 & 145808249 & 422341614 \\
\hline Durango/Norte & $5.18 \%$ & $1.50 \%$ & $2.87 \%$ & $1.10 \%$ & $1.04 \%$ \\
\hline Durango/RN & $1.54 \%$ & $0.30 \%$ & $0.42 \%$ & $0.22 \%$ & $0.18 \%$ \\
\hline
\end{tabular}

* Cifras en millones de pesos.

Fuente: Aboites Aguilar (en prensa).

38 Por primera vez se incluye el año de 2005 en atención a la mencionada escasez de fuentes. La serie disponible cubre el periodo 1995-2006. Así, se tomó 1997 y el año más alejado posible, en este caso 2005, para aproximarse a la tendencia general. No se tomaron en cuenta ni 1995 ni 1996 considerando la grave crisis derivada de los llamados "errores de diciembre" de 1994, ni tampoco 2006, en vista de la incongruencia de sus cifras. La serie se halla en CEFP-CD. 
Como se puede apreciar en el cuadro 4, la trayectoria tributaria local no contradice la tendencia descendente vista en el primer apartado de este trabajo. Durango recaudó cada vez menos ISR, que es un impuesto federal, vale insistir. Claro está que en este fenómeno intervienen las peculiaridades del impuesto mencionado, que hacen imposible considerarlo como mero espejo de la economía. Pero en este caso sí parece que la recaudación descendió de la mano del descenso de la economía local. Una manera de mostrarlo, además de la disminución porcentual de la recaudación duranguense en el total norteño y en el total nacional, es notando cómo se ensancha la distancia del monto de la recaudación del ISR lograda en Durango con respecto a la de Nuevo León: de ser dos veces y media superior en 1930, la de Nuevo León llegó a ser veintiún veces superior en 1961; la tendencia no desistió pese a la pequeña alza duranguense que se aprecia en 1979, pues en 1997 la de Nuevo León era cuarenta veces superior, y cuarenta y tres veces en $2005{ }^{39} \mathrm{El}$ cuadro agrega un indicio que llama la atención: que todavía en 1979 Durango recaudaba más ISR que Baja California Sur, pero desde 1997 la relación se invirtió. Para 2005 la entidad peninsular recaudaba más del doble que Durango. Así que desde 1997 Durango ocupaba por primera vez la última posición en el escenario norteño en este ramo. Como se puede apreciar, la recaudación tributaria federal se suma a la trayectoria descendente vista antes en cuanto a la población y la economía locales.

En torno a la cuestión fiscal surgen numerosas preguntas. Varias de ellas podrían desahogarse mediante la reconstrucción cuidadosa de la historia fiscal estatal, cuya trayectoria da la impresión de ser muy semejante a la de estados como Hidalgo y Yucatán, boyantes a principios del siglo xx y luego relegados a lo largo del mismo siglo. Una de esas preguntas es precisamente cómo explicar la baja recaudación del ISR y de otros impuestos federales,

39 La diferencia abismal entre el monto de recaudación de Durango y el de Nuevo León sirve para insistir en la dificultad si no es que en la imposibilidad de tomar el indicador tributario como reflejo de la marcha de la economía. En 2000 el PIB de Nuevo León no era 43 veces, sino apenas 5.9 veces superior al de Durango. Por tal razón, se afirma que el monto de la recaudación tributaria tiene otras explicaciones. Los montos del PIB de ambas entidades, en Inegi (s/f), cuadro 1. 
así como las características de la recaudación de impuestos locales (predial, de manera prioritaria); otra es cuál ha sido la relación entre la escasa capacidad de recaudación de impuestos federales y el monto de las participaciones federales que cada año entrega la Secretaría de Hacienda (el gobierno federal) al Gobierno del Estado y a los municipios. No hay que olvidar que ese mecanismo de redistribución tributaria, el llamado federalismo fiscal, ganó fuerza después de 1973-1980.

\section{COMENTARIOS FINALES}

¿Acaso por su trayectoria demográfica y económica puede proponerse que Durango es en realidad el estado menos norteño del Norte? Quizá tengan razón los estudiosos de la migración que excluyen a Durango del Norte y lo ubican en la región tradicional, la que expulsa al mayor número de emigrantes, según se vio. Quizá también de esa manera pueda entenderse el epígrafe de este trabajo, que recoge la postura de algunos líderes políticos y empresariales locales. ¿Qué ideas tienen los duranguenses sobre sí mismos y sobre Chiapas, y qué significa la identificación de su entidad con la entidad sureña? Da para hacer una investigación respecto a las percepciones de los norteños acerca del propio Norte y del resto del país.

Otra cuestión es precisar la cronología del declive duranguense. Hay indicios demográficos y económicos que ubican ese origen en las tres o cuatro décadas posteriores a la revolución de 1910. ¿Qué tan grave fue la afectación de la economía local a causa del movimiento revolucionario y cuáles fueron sus principales secuelas? A mi modo de entender, no hay que insistir mayormente en el impacto revolucionario. Como se intentó mostrar, otros fenómenos, como el saldo migratorio negativo, parecen más significativos. Más bien hay que preguntarse qué actividades explican la caída de la economía local durante la primera mitad del siglo, en especial durante la década de 1940. ¿Se sostiene la hipótesis general expuesta al inicio de este trabajo acerca de la matriz rural de la decadencia duranguense? Por otro lado, ¿qué explica 
el deterioro tributario tan evidente al final del siglo, o acaso el ISR no es buen indicador? ¿Qué actividades económicas explican tan baja recaudación?, ¿minería, explotación forestal, agricultura temporalera, ganadería, servicios? ¿Qué relación hay entre este escenario económico y el carácter de la clase propietaria y empresarial tildada, al menos, de "retraída"?, ¿qué significa "retraída”? A veces parece que es sinónimo de inexistente o, al menos, de muy temerosa, o conservadora en extremo.

Otra pregunta surge en torno al singular movimiento estudiantil de 1966. ¿Cómo se conecta la geografía histórica duranguense, al menos la del siglo xx, con el carácter de dicho movimiento juvenil? ¿Acaso el radicalismo de izquierda más bien brotó en las zonas norteñas más prósperas? ¿Vale la pena insistir en esa probable conexión, o acaso es preferible ahondar en la historia cultural, como lo propone el estudioso Palacios Moncayo? Él insiste en el conservadurismo dominante en Durango y en la gran influencia de que ha gozado la jerarquía católica. No hay que olvidar que si Sonora fue cuna del anticlericalismo posrevolucionario, Durango se distingue por el alzamiento cristero durante la década de $1930{ }^{40}$

Un último apunte. La dificultad duranguense del siglo xx recuerda la precaria situación que atravesó la capital de la Nueva Vizcaya después de 1632, cuando dio inicio el auge del entonces nuevo mineral de Parral. En esa ocasión, Durango se vació y aun los gobernadores emigraron a Parral y más tarde a la villa de Chihuahua; no regresaron sino hasta 1761. En 1649 el gobernador afirmaba que Durango estaba acabado y que solo se sostenía "gracias a su catedral”. ¿Es la sangría migratoria y el declive económico duranguense del siglo xx una reiteración de aquel episodio colo-

40 Sobre los cristeros locales, véase Avitia Hernández (2005); sobre el lugar de la Iglesia católica en el "conservadurismo" duranguense, véase Palacios Moncayo (2013), pp. 164167; también Ornelas (2010), p. 38. El mencionado arzobispo López Aviña, fallecido en 2004, fue tutor político de otro sacerdote duranguense que llegó a ser arzobispo primado de México en 1995, el más alto cargo de la jerarquía eclesiástica mexicana. Se trata, por supuesto, de Norberto Rivera Carrera (Tepehuanes, 1942). Dados esos antecedentes, no sorprende que desde hace años la catedral de Durango dedique uno de los altares a los mártires cristeros de Chalchihuites (agosto de 1926), canonizados por el papa Juan Pablo II en mayo de 2000.

41 En Vallebueno Garcinava (2005), p. 44. 
nial? ¿Es ahora el gobierno federal una especie de nueva catedral, aunque una parte de los duranguenses sigan aferrados a la vieja catedral?

Ojalá un joven historiador ahonde, precise e incluso, eche por tierra esta gruesa caracterización del componente duranguense de la historia norteña del siglo xx.

\section{ENTREVISTAS}

Contreras Casas, Jorge (Durango, 1939). Durango, sábado 21 de noviembre de 2015.

Escudero Gómez, Alberto (Aguascalientes, 1945). Durango, sábado 21 de noviembre de 2015 y domingo 17 de julio de 2016.

Palacios Moncayo, Miguel (Durango, 1944). Durango, viernes 20 de noviembre de 2015.

Rodarte, Juventino (Durango, 1939). Durango, viernes 20 de noviembre de 2015; y correos electrónicos de 19-23 de noviembre de 2015.

Vargas Quiñones, Rubén (El Salto, Pueblo Nuevo, Durango, 1945). Durango, viernes 20 de noviembre de 2015.

\section{BIBLIOGRAFÍA}

Aboites Aguilar, L. (2013). El norte entre algodones. Población, trabajo agrícola y optimismo en México, 1930-1970. México: El Colegio de México.

----- (en prensa). Estudio sobre geografía tributaria mexicana, 1788-2005.

Acosta Zavala, A. (2015). Así lo recuerdo. Torreón: Imprenta Río Nazas.

Almaraz Alvarado, A. (2007). Origen y continuidad de los empresarios de Mexicali, Baja California. Tesis de Doctorado en Ciencias Sociales. Guadalajara: Centro de Investigaciones y Estudios Superiores en Antropología Social.

Anuario estadístico de los Estados Unidos Mexicanos, 1970-1971

(1973). México: Secretaría de Industria y Comercio. 
Appendini, K. (s/f). Producto bruto interno por entidades federativas, 1900, 1940, 1950 y 1960. México: El Colegio de México (mimeo).

Arreola Valenzuela, A. (1995). Comunicaciones y cambios estructurales durante el porfiriato. En M. G. Rodríguez et al., Durango (1840-1915). Banca, transportes, tierra e industria (pp. 35-58). Monterrey: Universidad Autónoma de Nuevo León/Universidad Juárez del Estado de Durango.

Avitia Hernández, A. (2003). La montaña de las ilusiones. Historia del cerro de Mercado. México: Impresos Castellanos.

---- (2005). El caudillo sagrado. Historia de las rebeliones cristeras en el estado de Durango (segunda edición corregida). México. ---- (2013). Historia gráfica de Durango. La hegemonía del autoritarismo (Vol. 5). Durango: Gobierno del Estado.

Centro de Estudios de las Finanzas Públicas de la Cámara de Diputados (CEFP-CD). Cuaderno de Información Oportuna Regional 1995-2006, Inegi. Recuperado el 14 de enero de 2017, de http:// www3.diputados.gob.mx/camara/001_diputados/006_centros_de_estudio/02_centro_de_estudios_de_finanzas_publicas_11/005_indicadores_y_estadisticas/03_estatales/04_recaudacion_de_impuestos_federales_por_entidad_federativa

Cerutti, M. (1997). La Compañía Industrial Jabonera de La Laguna. En C. Marichal, \& M. Cerutti (Comps.), Historia de las grandes empresas en México, 1850-1930 (pp. 167-199). México: Fondo de Cultura Económica/Universidad de Nuevo León.

---- (2006). La construcción de una agrociudad en el noroeste de México. Ciudad Obregón (1925-1960). Secuencia, 64 (eneroabril), pp. 113-143.

Cerutti, M., \& Almaraz, A. (Coords.) (2013). El algodón en el norte de México (1925-1975). Impactos regionales y en la política nacional de industrialización. Tijuana: El Colegio de la Frontera Norte/Universidad Autónoma de Nuevo León.

Carrillo Rojas, A. (2013). Agua, agricultura y agroindustria. Sinaloa en el siglo XX, Culiacán, Universidad Autónoma de Sinaloa, Universidad Autónoma de Nuevo León. 
Carrillo Rojas, A., \& Rivas Sada, E. L. (Coords.) (2016). Agricultura empresarial en el norte de México (siglo xx). Actores y trayectoria de la economía regional. México: Asociación de Historia Económica del Norte de México/Plaza y Valdés.

Confederación de Cámaras Nacionales de Comercio, Servicios y Turismo (Concanaco) (1941). Cámara Nacional de Comercio e Industria de la ciudad de Durango, 1915-1940. México: Imprenta La Esfera (mayo).

Consejo Nacional de Población (Conapo) (2005). Migración MéxicoEstados Unidos. Panorama regional y estatal. México: Consejo Nacional de Población.

Correa Villanueva, J. L. (1986). La liquidación de Fundidora Monterrey y la reconversión industrial. Cuadernos Políticos, 47 (julioseptiembre), pp. 41-56.

Crónica Durango (s.p.i.). Crónica del segundo año de gobierno [de Hector Mayagoitia Domínguez].

Durango (1997). Durango: a 30 años del cerro. Concurso estatal de ensayo. Durango: Universidad Juárez del Estado de Durango.

---- (1968). La economía del estado de Durango. México: Banco de Comercio, S. A. (Colección de Estudios Económicos Regionales).

(1976). La economía del estado de Coahuila. México: Banco de Comercio, S. A. (Colección de Estudios Económicos Regionales).

Enríquez, I. C. (1945). Democracia económica. México: Porrúa.

Estadísticas históricas de México (вHм) (2014). Aguascalientes: Instituto Nacional de Estadística y Geografía (versión digital). Gamio, M. (1930). Mexican Immigration to the United States. A Study of Human Migration and Adjustment. Chicago: University of Chicago Press.

Garza, G. (2005). La urbanización de México en el siglo xx. México: El Colegio de México.

Gómez Villanueva, A. (2015). El campo que yo conocí. La tierra, los hombres, la política. Memorias. México: Sociedad Mexicana de Geografía y Estadística/Miguel Ángel Porrúa/Gobiernos de los estados de Chihuahua y Durango. 
González Casanova, P. (2006). Colonialismo interno: una redefinición. En A. A. Boron, Javier Amadeo, \& S. González (Comps.), La teoría marxista hoy: problemas y perspectivas (pp. 409-434). Buenos Aires: Consejo Latinoamericano de Ciencias Sociales. Guerra, F.-X. (1988). México: del Antiguo Régimen a la Revolución (Vol. 2). México: Fondo de Cultura Económica.

Instituto Nacional de Estadística y Geografía (Inegi) (1993). Sistema de cuentas nacionales de México. Producto interno bruto por entidad federativa. Aguascalientes: Instituto Nacional de Estadística y Geografía.

----- (s/f). Sistema de cuentas nacionales de México. Producto interno bruto por entidad federativa, 1997-2002. Aguascalientes: Instituto Nacional de Estadística y Geografía.

Jones, Jr., O. L. (1988). Nueva Vizcaya. Heartland of the Spanish Frontier. Albuquerque: New Mexico University Press.

Lucero González, S. A. (2002). Más allá del espejo de la memoria. Los estudiantes universitarios de Durango: trayectorias institucionales y manifestaciones en la vida política y social, 19501966. México: Universidad Juárez del Estado de Durango/Plaza y Valdés.

Memoria Durango (1957). Memoria de labores del primer año de gestión administrativa del C. Francisco González de la Vega, gobernador constitucional del Estado de Durango. Septiembre 15, s.p.i.

(1959). Memoria de labores del tercer año de gestión administrativa del C. Francisco González de la Vega, gobernador constitucional del Estado de Durango. Septiembre 15, s.p.i.

(1969). Primera memoria del estado de la administración pública. Ingeniero Alejandro Páez Urquidi. Durango, s.e., 15 de septiembre.

----- (1971). Tercera memoria del estado de la administración pública. Ingeniero Alejandro Páez Urquidi. Gobernador constitucional del estado, Durango, s.e., 15 de septiembre.

Meza Ponce, A. (1984). El movimiento urbano popular en Durango. Nueva Antropología, 24 (junio), pp. 89-98. 
Mijares Verdín, E. (1996). Ensayo. Durango: a 30 años del cerro. Concurso estatal de ensayo (pp. 9-47). Durango: Universidad Juárez del Estado de Durango.

Moncada, C. (1979). Cayeron: México: Calypso.

O Holguín, J. de la (2015). Álvaro Ríos. El agrarista de las caravanas rojas. Durango: Artes Gráficas de México.

Ornelas, C. (2010). Durango 70: fracaso de una revuelta social. Durango: Universidad Juárez del Estado de Durango.

Palacios Moncayo, M. (2006). Durango: economía, sociedad, política y cultura. Durango: Universidad Juárez del Estado de Durango.

----- (2013). Cultura y dominación en Durango. Durango: Universidad Juárez del Estado de Durango.

Ramos Salas, J. (2009). Entre el esplendor y el ocaso algodonero. Ensayo sobre el desarrollo urbano de Torreón. Saltillo: Consejo Editorial del Estado.

Ramírez Sáiz, J. M. (1986). Reivindicaciones urbanas y organización popular. El caso de Durango. Estudios Demográficos y Urbanos, I: 3 (septiembre-diciembre), pp. 399-421.

Rivas Sada, E. L. (2011). Cambio tecnológico, dinámica regional y reconversión productiva en el norte de México. La Comarca Lagunera, 1925-1975. Tesis de doctorado. Madrid: Instituto Universitario y de Investigación Ortega y Gasset.

Sobrino, J. (2010). Migración interna en México durante el siglo xx. México: Consejo Nacional de Población.

Vallebueno Garcinava, M. F. J. (2005). Civitas y URBs: la conformación del espacio urbano de Durango. Durango: Instituto de Cultura de Durango.

Villa Guerrero, G. (1999). La minería en la era del progreso y del trabajo (Durango, 1880-1910). En G. E. Cano, \& M. Cerutti (Coords.), Porfiriato y revolución en Durango (pp. 81-126). Durango: Universidad Juárez del Estado de Durango.

Walsh, C. (2008). Building the Borderlands. A Transnational History of Irrigated Cotton along the Mexico-Texas Border. College Station/Texas A\&M University Press. 